\section{Protopathic Pain}

Kerry Donnelly

VA WNY Healthcare System, University of Buffalo (SUNY) Behavioral Health Careline (116B), Buffalo, NY, USA

\section{Definition}

A variant of nociceptive pain (pain resulting from ongoing activation of primary afferent neurons by noxious stimuli), protopathic pain is transmitted by $\mathrm{C}$ fibers to the spinal cord. C-fibers are unmyelinated, small-diameter, and slow-conducting, resulting in poorly localized, dull, aching pain. The fibers are sensitive to mechanical, thermal, and chemical stimuli, resulting in diffuse pain which is particularly sensitive to opioid therapy.

\section{Cross-References}

Epicritic Pain

\section{References and Readings}

McCaffery, M., \& Pasero, C. (1999). Pain clinical manual (2nd ed.). St. Louis: Mosby. 